ORIGINAL PROF-2182

\title{
LAPAROSCOPIC CHOLECYSTECTOMY;
}

Per-operative factors responsible for difficulty in performance and conversion

\author{
Dr. Pervez Iqbal, Dr. Ayaz Anmed Memon, Dr. Khawar Saeel Jamali, Dr. Ubedullah Shaikh, Dr. Abdul Waqar Anmed Qureshi.
}

ABSTRACT.....Objective: The objective of this study is to determine the per-operative factors responsible for difficulty in performing laparoscopic cholecystectomy and lead to conversion. Study Design: Prospective analysis study. Place and Duration of study: This study was carried out in General Surgery Department of Dow University Hospital Ojha Campus and Civil Hospital Karachi, from Jan 2011 to July 2012. Methodology: This study consisted of one hundred \& forty six patients with gallstone disease. All patients had full clinical examination and right hypochondrium was especially examined for assessment of murphy's sign, palpable mass and visceromegaly. Base line and specific investigations were done in all patients especially ultrasound of abdomen as diagnostic modality and for assessment of gallstone disease. Inclusion criteria was that all patients diagnosed as case of gallstone disease. LC procedure was not attempted in patients with history of abdominal surgery, pregnant ladies due to risk of foetal loss, carcinoma of gall bladder acute pancreatitis, obstructive jaundice and unfit patients for general anesthesia. Results: Out of 146 patients included in this study 133 were female $(91 \%)$ and 13 male (9\%); with female to male ratio of $10.2: 1$. The mean age was $39.21+6.20$ years. Per Operative findings were adhesions in calot's triangle $24(16.43 \%)$ cases, severe \& tight adhesions around gallbladder and calot's triangle $21(14.38 \%)$ cases, obscured anatomy in calot's triangle $17(11.64 \%)$ cases, intrahepatic gallbladder $11(7.53 \%)$ cases, adhesions around gallbladder $26(17.80 \%)$ cases, empyema $13(8.90 \%)$ cases, mucocele $9(6.16 \%)$ and anatomical variation $14(9.58 \%)$ cases. We observed out of 21 patients who had Severe \& tight adhesions around gallbladder and calot's triangle, lead to difficulty in performing laparoscopic cholecystectomy in $11(52.38 \%$ ) cases followed by 17 cases of obscured anatomy in calot's triangle and 14 cases anatomical variation also lead to performing difficult laparoscopic cholecystectomy in $6(35.29 \%)$ and $5(35.71 \%)$ cases respectively. Four (2.73\%) cases out of 146 had to be converted to the open cholecystectomy procedure. Conclusions: We conclude our study revealed that various peroperative factors which make the difficult laparoscopic procedure and lead to open cholecystectomy are severe adhesions in calot's triangle, severe \& tight adhesions around gallbladder and obscured anatomy in calot's triangle.

Key words: Laparoscopic cholecystectomy, Conversion rate, Factor, Open cholecystectomy.

Article Citation

Iqbal P, Memon AA, Jamali KS, Shaikh U, Qureshi AWA. Laparoscopic Cholecystectomy; Per-operative factors responsible for difficulty in performance and conversion. Professional Med J 2013;20(3): 444-449.

\section{INTRODUCTION}

Nowadays surgery is modernized into minimally invasive techniques. Laparoscopic Cholecystectomy has now replaced open cholecystectomy as the firstchoice of all surgeons ${ }^{1}$. History of laparoscopic surgery is attractive and long. Kelling created a main laparoscopic camera chip in $1987^{2}$. Cholecystectomy due to gallstone is one of the most commonly performed surgical procedures all over the world. In modern era, swift changes in the treatment of gallstones since 1987, when first laparoscopic cholecystectomy was performed ${ }^{3}$. In Pakistan first laparoscopic cholecystectomy was performed in $1991^{4}$.

The day by day increasing skills in laparoscopic cholecystectomy is leading to more problems coming up while attempting complicated cases $^{5}$. The various peroperative factors that make laparoscopic cholecystectomy a technically difficult procedure like acute cholecystitis, empyema gall bladder, gangrenous cholecystitis, fibrosed gallbladder, severe adhesions in calot's triangle and intrahepatic gall bladder $^{6-8}$. These problems are difficult to assess preoperatively but are frequently faced during laparoscopic procedure and responsible for major difficulty in performing the surgery.

The current study was aimed to evaluate various intra operative predictive factors encountered during laparoscopic cholecystectomy which are responsible for difficulty in performing laparoscopic cholecy- 
stectomy and conversion to open cholecystectomy.

\section{MATERIAL \& METHODS}

This observational study includes one hundred \& forty six patients with gallstone disease, admitted through the outpatient department, as well as from casualty department and referred from medical wards of Dow University Hospital OJHA Capmus Karachi, Pakistan, for laparoscopic cholecystectomy, from Jan 2011 to July 2012.

All patients had full clinical examination and right hypochondrium was especially examined for assessment of murphy's sign, palpable mass and visceromegaly. Base line and specific investigations were done in all patients especially ultrasound of abdomen as diagnostic modality and for assessment of gallstone disease. Inclusion criteria was that all patients diagnosed as case of gallstone disease. LC procedure was not attempted in patients with history of abdominal surgery, pregnant ladies due to risk of foetal loss, carcinoma of gall bladder acute pancreatitis, obstructive jaundice and unfit patients for general anesthesia. Results were prepared with help of tables and graphs. Data was analyzed through SPSS software.

\section{RESULTS}

146 cases of gallstone disease were operated through laparoscopic cholecystectmy procedure. Out of 146 patients included in this study 133 were female (91\%) and 13 male (9\%); with female to male ratio of 10.2:1. There was wide variation of age ranging from a minimum of 25 years to 65 years. The mean age was $39.21+6.20$ years. The patients presented with pain in $\mathrm{RHC} 91 \%$, pain in RHC along with pain in epigastrium $75 \%$, Nausea \& Vomiting $19 \%$, dyspepsia $47 \%$ and fever in $8 \%$ of cases. The abdominal ultrasound report showed single stone in $34(23.28 \%)$ patients whereas multiple stones in $112(76.71 \%)$ patients and associated findings included impacted stone at the neck of gallbladder in $4(2.73 \%)$, thick wall gallbladder in $75(51.36 \%)$ patients, empyma gallbladder $13(8.9 \%)$ patients, mucocele $6(4.1 \%)$ patients, contracted gallbladder $33(22.60 \%)$ cases and adhesions around gallbladder in 48(32.87\%) patients (Table No.I).

\begin{tabular}{|c|c|c|}
\hline Variable & Number of Patients & \%age \\
\hline \multicolumn{3}{|l|}{ Gender } \\
\hline Male & 13 & $9 \%$ \\
\hline Female & 133 & $91 \%$ \\
\hline \multicolumn{3}{|l|}{ Age } \\
\hline 25 to 40 years & 69 & $47.26 \%$ \\
\hline 41 to 55 years & 55 & $37.67 \%$ \\
\hline 56 to 65 years & 22 & $15.06 \%$ \\
\hline \multicolumn{3}{|l|}{ Presenting Complains } \\
\hline $\begin{array}{l}\text { Pain in Right } \\
\text { Hypochondirum }\end{array}$ & 132 & $90.4 \%$ \\
\hline $\begin{array}{l}\text { Pain in RHC \& } \\
\text { Epigastrium }\end{array}$ & 110 & $75.34 \%$ \\
\hline Nausea \& Vomiting & 28 & $19.17 \%$ \\
\hline Dyspepsia & 69 & $47.26 \%$ \\
\hline Fever & 12 & $8.21 \%$ \\
\hline \multicolumn{3}{|c|}{ Abdominal Ultrasound Findings } \\
\hline Single Stone & 34 & $23.28 \%$ \\
\hline Multiple Stone & 112 & $76.71 \%$ \\
\hline $\begin{array}{l}\text { Impacted Stone at } \\
\text { Neck of Gallbladder }\end{array}$ & 4 & $2.73 \%$ \\
\hline Thick Wall Gallbladder & 75 & $51.36 \%$ \\
\hline Empyema & 13 & $8.9 \%$ \\
\hline Mucocele & 6 & $4.1 \%$ \\
\hline Contracted Gallbladder & 33 & $22.66 \%$ \\
\hline
\end{tabular}

Per Operative findings were adhesions in calot's triangle $24(16.43 \%)$ cases, severe \& tight adhesions around gallbladder and calot's triangle $21(14.38 \%)$ 
cases, obscured anatomy in calot's triangle $17(11.64 \%)$ cases, intrahepatic gallbladder $11(7.53 \%)$ cases, adhesions around gallbladder $26(17.80 \%)$ cases, empyema 13(8.90\%) cases, mucocele $9(6.16 \%)$ and anatomical variation $14(9.58 \%)$ cases. We observed out of 21 patients who had Severe \& tight adhesions around gallbladder and calot's triangle, lead to difficulty in performing laparoscopic cholecystectomy in 11(52.38\%) cases followed by 17 cases of obscured anatomy in calot's triangle and 14 cases anatomical variation also lead to performing difficult laparoscopic cholecystectomy in 6(35.29\%) and 5(35.71\%) cases respectively (TableII).

\begin{tabular}{|l|c|c|c|}
\hline \multicolumn{1}{|c|}{$\begin{array}{c}\text { Over all per } \\
\text { Operative } \\
\text { Finding }\end{array}$} & $\begin{array}{c}\text { No. of } \\
\text { patients } \\
\text { (n=146) }\end{array}$ & $\begin{array}{l}\text { No. Case in } \\
\text { which difficulty } \\
\text { in performing } \\
\text { laparoscopic } \\
\text { cholecystectomy }\end{array}$ & $\begin{array}{c}\text { Conver- } \\
\text { sion } \\
\text { rate }\end{array}$ \\
\hline $\begin{array}{l}\text { Adhesions in } \\
\text { calot's trangle }\end{array}$ & $24(16.43 \%)$ & $5(20.83 \%)$ & - \\
\hline $\begin{array}{l}\text { Severe \& tight } \\
\text { adhesions adound } \\
\text { gallbladder and } \\
\text { calot's triangle }\end{array}$ & $21(14.38 \%)$ & $11(52.38 \%)$ & 1 case \\
\hline $\begin{array}{l}\text { Obscured anatomy } \\
\text { in calot's triangle }\end{array}$ & $16(10.95 \%)$ & $6(35.29 \%)$ & 1 case \\
\hline $\begin{array}{l}\text { Intrahepatic } \\
\text { gallbladder }\end{array}$ & $11(7.53 \%)$ & - & - \\
\hline $\begin{array}{l}\text { Adhesions around } \\
\text { gallbladder }\end{array}$ & $26(17.80 \%)$ & - & - \\
\hline $\begin{array}{l}\text { Cholecysto- } \\
\text { duodenal Fistula }\end{array}$ & $1(0.68 \%)$ & $1(0.68 \%)$ & 1 case \\
\hline Empyema & $13(8.90 \%)$ & $2(15.38 \%)$ & - \\
\hline Mucocele & $9(6.16 \%)$ & $1(11.11 \%)$ & - \\
\hline $\begin{array}{l}\text { Contracted gall } \\
\text { bladder }\end{array}$ & $11(7.5 \%)$ & $2(18.18 \%)$ & - \\
\hline $\begin{array}{l}\text { Anatomical } \\
\text { variation }\end{array}$ & $14(9.58 \%)$ & $5(35.71 \%)$ & 1 case \\
\hline
\end{tabular}

Table-Il. Per operative finding
Four $(2.73 \%)$ cases out of 146 had to be converted to the open cholecystectomy procedure.

\section{DISCUSSION}

Since 1989, Iaparoscopic technique has been choice in the treatment of symptomatic gall stone. Some cases of the planned laparoscopic cholecystectomy needs conversion due to multiple factors ${ }^{9}$ like pathology, the level of skill of the surgeon, and technical factors all can play major role in the decision for conversion.

This study explore the experience of 146 patients that underwent laparoscopic cholecystectomy. Number of female was dominant over the male as estrogen can increase cholesterol and reduce gallbladder motility. Women who are pregnant or who take birth control pills or hormone replacement therapy have higher levels of estrogen and may be more likely to develop gallstones and ratio of male to female ratio was $1: 10.23$. Siddiqui $\mathrm{K}^{10}$ reported male to female ratio of 1:5.2 which is quite different from present study. Maximum number patients reported in the $4^{\text {th }}$ and $5^{\text {th }}$ decade of life with mean age was $39.21+6.20$ years in comparison with other study where the age range was $16-59$ years with mean $37 \pm 10$ years ${ }^{11}$.

Clinically patients mostly presented with pain in right hypochondrium and epigastrium. In our study patients commonly presented with pain in $\mathrm{RHC} 91 \%$, pain in RHC along with pain in epigastrium $75 \%$, Nausea \& Vomiting $19 \%$, dyspepsia $47 \%$ and fever in $8 \%$ of cases. Laghari et $\mathrm{al}^{12}$ reported the patients presented with upper abdominal pain either in right hypochonderum $(51.67 \%)$ or in right hypochondrium and epgastrium (29.17\%) or epigastrium (19.17\%).

The clinical parameters were further evaluated by ultrasound scan. This showed mostly multiple stones in $112(76.71 \%)$ cases and associated status of gallbladder like thick wall gallbladder in $75(51.36 \%)$ cases followed by contracted gallbladder 33(22.60\%) 
cases, empyema gallbladder 13(8.9\%) casess, mucocele $6(4.1 \%)$ cases and impacted stone at the neck of gallbladder in 4(2.73\%) cases. An international study conducted by $\mathrm{Ji}$ et $\mathrm{al}^{13}$. Reported ultrasound finding were multiple stones in $69.71 \%$, thick wall gallbladder in $41.67 \%$ and adhesions in $35 \%$ of cases.

Some national and international studies investigated risk factors for difficulty in performing laparoscopic cholecystectomy and conversion ${ }^{14,15,16}$, which have reported variables that may appear significant in one study but not in another. These variations may be due to the particular population, differences in surgical skill and differences in training systems ${ }^{16}$.

Severe \& tight adhesions around gallbladder, calot's triangle and obscured anatomy in calot's triangle are two of the most important reasons of difficulty in performing laparoscopic cholecystectomy procedure. Our study observed severe tight adhesion in $21(14.38 \%)$ cases due to repeated attacks of acute Cholecystitis leading to difficult identification of structures of calot's triangle, only one patient was converted. However the study of Soomro $\mathrm{AH}^{17}$ reported per-operative findings of adhesion of gall bladder with surrounding structure (Calot's triangle, stomach, colon and omentum in $47.1 \%$ cases).

The most common reason for conversion was difficulty in performing dissection with failure to recognize a clear anatomy either due to sever inflammation, adhesions or uncertainty of anatomical land marks ${ }^{18}$. In our study $16(10.95 \%)$ cases had obscured anatomy in calot's triangle, $6(35.29 \%)$ out of 16 cases there was difficulty in performing laparoscopic procedure and lead to conversion to open in one case. In 2012, a study conducted on 103 patients of acute cholecystitis by Rehan Masood ${ }^{19}$ at Rawalipindi reported 2(1.9\%) cases were converted to open due to difficult anatomy at calot's triangle.

In our study Cholecysto-duodenal Fistula found in one case and lead to conversion to open. However in the study of Shamim $\mathrm{M}^{20}$ reported over all 6.17\% conversions were due to dense adhesions between gallbladder and bowel. On conversion, one patient with bilio-digestive fistula (1.23\%); fistulous communication between the GB fundus and pylorus was excised along with cholecystectomy and primary repair of defect was done. With improved and advanced laparoscopy skills, biliodigestive fistulas is being managed laparoscopically with low morbidity and no mortality ${ }^{21,22}$. In our study over all conversion was $2.7 \%$.

\section{CONCLUSIONS}

Our study revealed that various peroperative factors which make the difficult laparoscopic procedure and lead to open cholecystectomy are severe adhesions in calot's triangle, severe \& tight adhesions around gallbladder and obscured anatomy in calot's triangle. However experience surgical team, careful dissection around gall bladder and in calot's triangle can make the laparoscopic procedure much easy and possible.

\section{Copyright@ 15 Feb, 2013.}

\section{REFERENCES}

1. Geraci G, Sciume C, Pisello F, Volsi FL, Facella T, Modica G. Trocar-related abdominal wall bleeding in $\mathbf{2 0 0}$ patients after laparoscopic cholecistectomy: Personal experience. J Gastroenterol 2006; 12(44): 7165-67.

2. Harrell AG, Heniford T. Minimally invasive abdominal surgery: lux et veritas past, present, and future. The American Journal of Surgery 2005;190:239-243.

3. Gondal KM, Akhtar S, Shah TA. Experience of laparoscopic cholecystectomy at Mayo Hospital, Lahore. Ann KE Med Coll 2002; 8:216-8.

4. Hinduja TK, Shaikh NA,Shaikh SM, Soomro I, Jalbani $\mathrm{MH}$. Early Laparoscopic Cholecystectomy. Professional Med J Mar 2008;15(1):162-7.

5. Jenkins PJ, Paterson HM, Parks RW, Garden OJ. Open cholecystectomy in the laparoscopic era. Br J Surg 2007; 94:1382-1385. 
6. Malik A, Laghari AA, Talpur KAH, Memon A, Malah Q. Laparoscopic cholecystectomy in empyema of gallbladder: An experience at Liaquat University Hospital Jamshoro , Pakistan. J Min Access Surg 2007:3:52-6.

7. Daniak CN, Peretz D, Fine JM, Wang Y, Meinke AK, Hale WB. Factors associated with time to laparoscopic cholecystectomy for acute cholecystitis. World $\mathrm{J}$ Gastroenterol 2008; 14(7): 1084-1090.

8. Siddiqui T, MacDonald A,Chong PS, Jenkins JT. Early versus delayed laparoscopic cholecystectomy for acute cholecystitis: a meta-analysis of randomized clinical trials. American J Surg 2008;195(1):40-7.

9. Sharma SK, Thapa PB, Pandey A, Kayastha B, Poudyal $S$, Uprety KR, Ranjit S. Predicting difficulties during laparoscopic cholecystectomy by preoperative ultrasound. Kathmandu University Medical Journal 2007;5(1): 8-11.

10. Siddiqui K, Khan AFA. Comparison of frequency of wound infection: open vs laparoscopic cholecystectomy. J Ayub Med Coll Abbottabad 2006;18(3):21-4.

11. Ahmad S, Aman Z, Akbar S, Zia-UI-Haq M, Khan MS. Port site hernia in laparoscopic cholecystectomy. J Med Sci 2011;19(1):9-11.

12. Laghari AA, Talpur KAH, Malik AM, Khan SA, Memon AI Laparoscopic cholecystectomy in complicated gallstone disease. Journal of J LUMHS 2008;18-24.

13. Ji W, Li LT, Wang ZM, Quan ZF, Chen XR, Li JS. A randomized controlled trial of laparoscopic versus open cholecystectomy in patients with cirrhotic portal

14. Ibrahim S, Hean TK, Ho LS. Risk factors for conversion to open surgery in patients undergoing laparoscopic cholecystectomy. World J Surg. 2006;30: 1698-704.

15. Pavlidis TE, Marakis GN, Ballas K. Risk factors influencing conversion of laparoscopic to open cholecystectomy. J Laparo Endosc Adv Surg Tech A. 2007; 17: 414-8.

16. Simopoulos C, Botaitis S, Polychronidis. Risk factors for conversion of laparoscopic to open cholecystectomy. Surg Endosc. 2005;19: 905-9.

17. Soomro AH, Memon AA, Devi B. Role of laparoscopic cholecystectomy in the management of acute cholecystitis. J LUMHS 2005.68-71.

18. Hanna MK, Mohammed K, Hindosh LN. Predictability of Conversion From Laparoscopic to Open Cholecystectomy: Retrospective Analysis of Risk Factors. Iraqi Postgraduate Med J 2010;9(1):25-31.

19. Masood R, Afridi ZUD, Masood K, Khan BA, Khurshied F. Cholecystectomy in Acute Gall bladder. J Postgrad Med Inst 2012; 26(2): 212-7.

20. Shamim M, Memon AS, Bhutto AA, Dahri MM. Reasons of conversion of laparoscopic to open cholecystectomy in a tertiary care institution. J Pak Med Assoc 2009;59:456-60.

21. Chowdhury HK. Laparoscopic management of Cholecystoenteric fistula: A report of nineteen cases. J Surg Pakistan 1999; 4: 5-6.

22. Tantia O, Bandyopadhyay SK, Sen B, Khanna S. Pericholecystic fistula: a study of $\mathbf{6 4}$ cases. Int Surg 2002; 87: 90-3. 
AUTHOR(S):

1. PROF. DR. PERVEZ IQBAL, FCPS

Professor of Surgery

Dow University Hospital Ojha Campus, Karachi.

2. DR. AYAZ AHMED MEMON, FCPS

Assistant Professor of Surgery

Dow University Hospital Ojha Campus, Karachi.

3. DR. KHAWAR SAEED JAMALI, FCPS

Associate Professor of Surgery

Dow University Hospital Ojha Campus, Karachi.

4. Dr. Ubedullah Shaikh

Senior Medical Officer

Dow University Hospital Ojha Campus, Karachi.

\section{Dr. Abdul Waqar Ahmed Qureshi}

Postgraduate Student

Dow University Hospital Ojha Campus, Karachi.

Correspondence Address:

Prof. Dr. Pervez Iqbal, FCPS

Professor of Surgery

Dow University Hospital Ojha Campus,

Main University Road, Karachi.

surgeonpervez@gmail.com

\section{PREVIOUS RELATED STUDIES}

Awais Shuja, Abid Bashir, Abid Rashid. LAPAROSCOPIC CHOLECYSTE-CTOMY; OPTIMAL TIMING FOR SURGERY IN ACUTE GALL STONE DISEASE (Original) Prof Med Jour 18(2) 237-242Apr, May, Jun 2011.

Faisal Bilal Lodhi, Riaz Hussain. LAPAROSCOPIC CHOLE-CYSTECTOMY; LOW-PRESSURE PNEUMO-PERITONEUM FOR SHOULDER-TIP PAIN (Original) Prof Med Jour 10(4) 266 - 270 Oct, Nov, Dec, 2003.

Jahangir Sarwar Khan, Jawad Zahir, Asifa Dian, Naveed Akhtar Malik, Usman qureshi, Muhammad Mussadiq Khan, Muhammad lqbal. LAPAROSCOPIC CHOLECYS-TECTOMY; RANDOMIZED, CONTROLLED TRIAL OF BUPIVACAINE INJECTION TO DECREASE PAIN. (Original) Prof Med Jour 16 (3) 321-326 Jul, Aug, Sep, 2009.

Jahangir Sarwar Khan, Hamid Hasan, Mohammad Iqbal. LAPAROSCOPIC CHOLECYCTECTOMY; COMMON BILE DUCT INJURY AFTER LEARNING CURVE (Original) Prof Med Jour 17(3) 373-378 Jul, Aug, Sep 2010.

Muhammad Zubair, Sultan Mehmood, Sumaira Kanwal, Riaz Hussain Dab. LAPAROSCOPIC ORCHIDOPEXY (Original) Prof Med Jour 15(1) 168 - 170 Jan, Feb, Mar, 2008.

Muhammad Akram, Muhammad Rehman Gulzar, Umer Farooq, Muhammad Ajmal Khan, Javaid Iqbal. LAPAROSCOPIC CHOLECYSTECTOMY OUTCOME IN PATIENTS WITH CO-MORBIDITY (Original) Prof Med Jour 16(2) 221-223 Apr, May, Jun, 2009.

Muhammad Rahim Bhurgri, Muhammad Jawaid Rajput, Syed Razi Muhammad. LAPAROSCOPIC CHOLECYSTECTOMY; FATE OF SPILLED BILE WITH GALLSTONES DURING LAPAROSCOPIC CHOLECYSTECTOMY (Original) Prof Med Jour 18(3) 361-365 Jul, Aug, Sep 2011.

Naveed Jabbar, M. Zafar Khan, Aftab Ahmed Ch. LAPAROSCOPIC APPENDICECTOMY; CLIP-CLOSURE OF APPENDIX STUMP (Original) Prof Med Jour 18(2) 233-236 Apr, May, Jun 2011.

Thakur K. Hinduja, Sher Mohammad Shaikh, Malick Hussain Jalbani, Nisar Ahmed Shaikh, Ishaque Soomro. EARLY LAPAROSCOPIC CHOLECYSTECTOMY; (Original) Prof Med Jour 15(1) 162 - 167 Jan, Feb, Mar, 2008. 